\title{
Kompensasie vir die invloed van die elektriese veldsterkte op die bepaling van die bewegingshoek van 'n vliegtuig
}

Ontrang 17 Oktober 1997; annaur 3 April 1998

\begin{abstract}
A ibstrinct
Using the earth's electrostatic field for aircraft attitude measurements

During flight large voltage differences can develop between isolated sensons on the wingtips of an aircraft. This is as a resull of charge differences in the atmosphere under the influence of the ecath's electrostatic field. These charge differences cren be uthilised for aireraft antude measurements. An electrostatic sensor has been developed to measure these charge differences. The system also inconporales a field compensator to minimise the influchese of changes in the atmospheric electrostatic field. To increase the sensitivity of the system, a radionctive soure is ased to ionise the surrounding aid; the reby increasing the number of locally ionised particles.
\end{abstract}

\section{INLEIDING;}

Die moontlikheid van 'n clektrostatiese sensor vir die meet van "n vliegtuig se bewegingshocke gedurende vlug is al in November 1972 deur M.L. Hill ${ }^{1.2}$ genoem. Ily was destyds verbonde alan dic John Hopkins Applied Physics Laboratory (APL) in Maryland. VSA. Spanningsverskille lussen twee sensors wat op die vlerkpunte van 'n vlicgluig geplatas is, word gemeet terwyl die vliegtuig in die elektrostatiese veld tussen die aarde en die ionosfeer vlieg. Radioaktiewe bronne word gebruik om die lug lokaal te ionisecr, sodat ckstra ione voorkom wal die ladingsverskille vergroot om sodoende' n groter sein te verkry. Dic ionosfeer is tipies sowat $350 \mathrm{kV}$ positicl' gelaai met betrekking tot dic aardoppervlakte. In matige weerstoestande en ook sekere vorms van onwecr, is die spanningsgradliënt vertikial georiënteer en in dic orde van $150 \mathrm{~V} / \mathrm{m}$ naby dic grond. Ilill het gedurende werklike vlugtoelse 'n radioakliewe bron, Polonium 210, as ioniseerder gebruik.

lly het ook al vroeg sy bedenkinge uitgespreck oor so 'n stelsel, aangesien te veel eksterne faktore die werking van die stelsel kan beïnvloed, malar die elfek van sodanige invloede is nie kwantitaticl bepalal nie. Potensiële invloede is byvoorbeeld die wecrsomstandighede, lugspoed, hoogte, temperatuur en vliegtuigdinamika, wat soms mocilik is om te meel en wiskundig te beskryl.

Heelwat ondersocke is al gedoen na die elektriese gedrag van dic atmosfeer en literatuur bestaan ten opsigte vall die invloed van die aarde se geleidingstrome, vertikale spanningsgradiënt, oortollige ladingdraers, en gelaaide deelljies as 'n funksic van hoogle.

Hierdie projek het ten doel om die onderliggende fisiese beginsels te verduidelik, self' $n$ lisiese stelsel te ontwikkel om die ladings te meet, en dan kwantitatief met die gemele data te oordeel wat die fisiese tekortkominge van so 'n stelsel is.

\section{AG'TER(;ROND}

Die hoogteverskil tussen twee clektrostaticse sensors op die vlerkpunte van 'n vliegluig veroorsalak 'n uitsetsein, walarvan die groolte 'n funksie is van onder meer dic rolhock van die vlerk. afistand tussen die sensors, elektriese veldsterkte in die atmosleer, die spoed warteen die ioniscerde ladings in die lug beweeg, asook die sterkte van die radioaktiewe bron.

Een vertikaalgeoriëntecrde kollektorplaat word alan clke punt van 'n vliegtuig se vlerke gemontecr. lesame me 'n radioakt iewe bron. Altwee kollektorplate is verbind alan 'n hoé-impedansicelektrometer wall die verskil in ladings lussen die lwee plate sal meet. Die radioakliewe bronne veroorsaak lokale ionisasie van die lug naby die vliegtuig se vlerkpunte. Hierdic geionisecrde ladings beweeg onder die invloed van die vertikale spanningsgradliënt, wat veroorsalk word deur die sowall $3.50 \mathrm{kV}$ positicfgelaaide ionosleer met betrekking tot die atardoppervlakte. I)ic negatiewe elek trone beweeg opwalarts na die positiewe ionosleer, terwyl die positiewe ione alwalarts na die alarde beweeg.

Sou die vliegtuig se vlerk horisontaal wees, sal eweveel ladings die linker-en die regterkantste kollektorplate bereik, en sal daar geen ladingsverskil wees nic. Indien die vliegluig egler teen 'n vaste rolhoek vlieg, bereik meer negallewe ladings die onderste kollektorplatat as bo. Net so sal meer positiewe ladlings dic boonste kollektorplaal bereik as onder. Hierdic ladingsverskille (alhoewel klein) veroorsalak 'n stroomvloci ( $1=Q^{\prime}=1$ ) wat deur die elektrometer gemeet kall word. Hoe groter die hoek, hoe groter word die oppervlakte van die kollektorplate wall die vertikaal bewegende ladings 'sien'. 'I Groter oppervlakle beteken dat meer ladings die kollektorplate bereik en gevolglik word die ladingsverskil en die gemele stroom groter. Ilierdie gemete stroom is dan 'n direkı lunksic van die vliegtuig se rollhock.

Iloe vinniger die vliegtuig vlieg, hoe meer na vore skuif die volume lug (met ladings) wal 'n effek op die kollektorplat se lading (en scinsterkte) het. Ook word ladlings van teenoorgestclde polariteit as wat die kollektorplaal ontvang in die lug agtergelaat. Die ladings herkombineer nie daldelik nie. met die gevolg dat dit hulle eie elektriese veld opwek wall die oorspronklike veld leenwerk. Dil word dus duidelik dal die vliegtuig se spoed ook 'n faktor word wat in berekening gehou moel word.

Sou die radioakticwe bronne 'n te swak lokale ionisasieveld veroorsalak, sal te min ladings by die kollektorplate beskikbaar wecs. Dit sal 'n lae scin-tot-ruis-verhouding tot gevolg hê. Sorg moet dus gedra word dat daar 'n minimum groolte ionisasieveld (en dus die minimum sterkte bron in $\mathrm{mCi}$ ) gebruik word om 'n aanvaarbare werkverrigting van die sensor te verseker. Solank al die radioaktiewe bronne dan dieselfide sterkte hel. sall die stelsel korrek lunksioneer. Vir klein verskille sal wel elekironies gekompenseer kin word

Verder kan die elektriese veldsterkle ook verander. Dit kan byvoorbecld die gevolg wees van dic tecnwoordigheid van Cumuluswolke, wal sterk ladingskeidingseicnskappe besit. Die 
gemete stroom sal dan 'n fout bevat wat albeeld op 'n verkeerde hock. Ilierdie projek stel die volgende metode voor om vir hierdie invloed ic kompenseer:

\section{KOMPENSASIE VIR VERANIDERINGE IN DIL ELEKTRIESE VELD}

Die doel is om die sensoreenheid toe te rus met 'n kompensecrer sodat die stelsel binne perke ongevoelig sal wees vir veranderinge in elektrostatiese veldsterkte. Die probleem word opgelos deur'n derde elektrostatiese sensor halaks met die eerste stel sensors te plaas en sodoende'n tweede lesing te verkry wat gebruik kan word om te kompenseer vir veranderinge. Dic metode word verduidelik alan die hand van ligutur 1

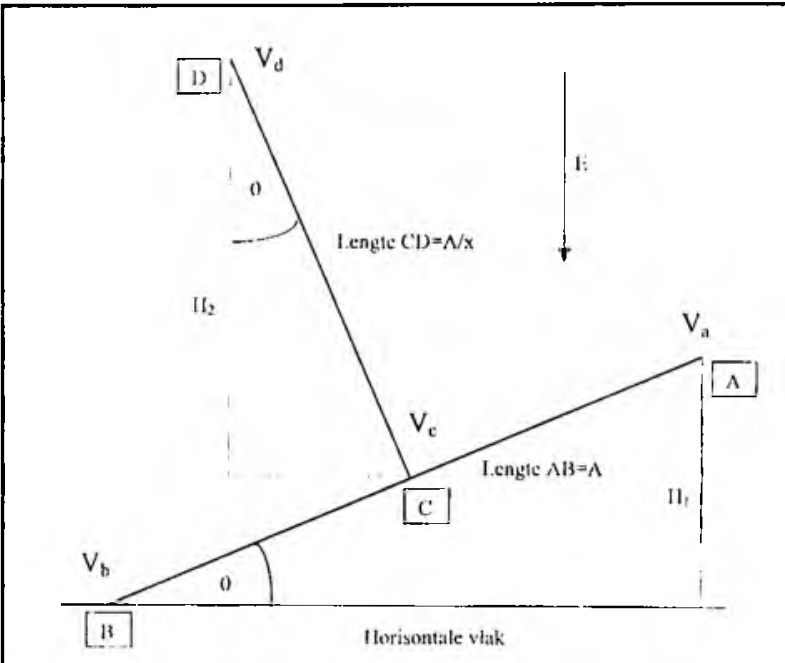

FIGUUR I: Fisiese uitleg vir kompensering.

Dic lyn AB stel die vliegtuig se vlerk voor wat 'n hoek $\theta$ met die horisontale vlak maak. Lyn DC is loodreg op lyn AB (met $B C=C A$ ). Die spannings $V_{a}, V_{k}, e n V_{u}$ is die seine wat op die kollektorplate (relatief tot dieselfele verwysing) gemeet word. $\mathrm{V}_{c}$ is blool die gemiddelde van $\mathrm{V}_{\mathrm{a}}$ en $\mathrm{V}_{\mathrm{b}}$. Sodoende word 'n vierde kollektorplaat met 'n radioaktiewe bron gespalar. Die vertikale elektriese veldkomponent is as E aangedui. Uit trigonometrie volg die volgende:

$$
\begin{aligned}
& \left(V_{a}-V_{b}\right)=E H_{1}=E A \sin \theta \\
& \left(V_{d}-V_{c}\right)=E H_{2}=E\left(\frac{A}{x}\right) \cos \theta \\
& \text { wiar } \quad V_{c}=\frac{1}{2}\left(V_{a}+V_{b}\right)
\end{aligned}
$$

Deur die veranderlike $\theta$ vanuil (1), (2) en (3) op te los, word die volgende uitdrukking verkry:

$$
\theta=\operatorname{bgtan}\left[\frac{V_{a}-V_{b}}{x\left(V_{a}-\frac{1}{2}\left(V_{a}+V_{b}\right)\right)}\right]
$$

Die veranderende elektrostatiese veld kom glad nie meer in die uitdrukking voor nic. Deur dus twee differensiële seine te meet en die uitdrukking van (4) te gebruik, word die gekompenseerde hock bereken wat onafhanklik is van die elektrostatiese veldsterkte. Die faktor $x$ is slegs daar om dic lengte van DC fisies mecr realisties te maak. In die eksperimentele opstelling wat hieronder beskryl word, is $x=2$.

\section{EKSPERIMENTELE OPSTELIING}

Die volgende cksperimentele opstelling word gebruik: "n llouphal van $3,5 \mathrm{~m}$ is vertikatal op 'n molorvoemige se dakrak gemontect. Dit is 'n poging om die motor se invloed op dic elcktrostatiese veld tot 'n minimum te beperk. (On' 'n vliegluig se vlerk te simuleer, is 'n dwarsplink, $1,5 \mathrm{~m}$ lank, bo-ilin dic houlpail gemonteer. Eersgenoemele kan deur midided vall "n skimierpunt geroleer word deur "n hock van ongeveer ()()". Dic elchtrostatiese sensors (geplats soos in ligutur | verduidelik) met die nodige seinkondisionering, 'I roltempogiro, asook 'n polensiometer om die werklike hock te meet wal as verwysing kan dien, is op die dwarsplank gemonteer. Die analoogseine word via afgeskermde dratad na onder gevoer, walar dil nal geskikte omsetting via die seriale poort vall 'n dialabbare rekenaar ingelees word. Na afloop van die eksperiment kin dic dala gereduseer en geanaliseer word. Ilierdie opstelling is heel eenvoudig en goedkoop. Ook verseker dit dat haie ditipunte onder verskeie weersomstandighede med hetreklik min mocite opgeneem kin word

Die lisiese gedeelte watrmee die laddings gemeel word. bestian uil 'n sirkelvormige kolicklorplatl, mel die radlioakticwe bronne in die middel daarvan gemonteer. Ilierdie gedeelte word aan die huitckant van die vlerk (in hierdic geval nou dic dwarsplank) verlikalal gemonteer met die radioaktiewe bronne wall na die buitekant kyk. Ook is daar 'n derde kollektorplatat op 'n vooral bepalade vertikale alstand bo die ander twee gemonteer, en word gebruik om intyds die elektrostalleso veldsterkte te hepaal.

llill se eksperimente is met hehulp valn radioakticwe Polonium 21()-illabronne gedoen. In terme van eksterne slraling op die mens is dit veilig. maar dil hou egler 'n hoe interne stralingsgevalar in. Die brome se hallilectyd is ook sowall vier mande, wal beleken dal die bronne gereeld vervang, en die betrokke meeltocrusting gereeld gekalibrecr moct word. Dic radioaktiewe bronne wall vir hicrdie projek gebruik word, is Kripton85 $3 \mathrm{mCi}$ betastralers. Dit hou 'n haie kleiner interne stralingsgevaar in en hel ook 'n hallecftyd van ongeveer tien jaar, sodat die minimum onderhoud op dic radioaklicwe bronne en die seinverwerking benodig word. Dit word op ' n groot skial in dic nywerheid gebruik.

'n Tempogiro sorg vir roltempo-inligting vann die dwarsplank. met die lisiese hoek wall deur middel van 'n potensiomeder gemeet word met 'n resolusie van $0.35^{\prime \prime}$. Die elektrostaliese versierkers waarmee die klein ladlingsverskille gemeet word. hel 'n ingangsimpedansie van 600$) \mathrm{M} \Omega 2$, 'n stroomresolusic van $6,1 \mathrm{pA}$ en 'n volskaalstroom valn $1,58 \mathrm{nA}$. Die grooltes valn die ladings wissel lussen ongeveer $3100790 \times 10^{10} \mathrm{C}$.

'n DS5000T Dallas-mikroverwerker word as ' 11 analoog-nasyfer-omseter gebruik. Ilicrdie mikroverwerker kan mel die seriale poon van 'n gewone draiaghare rekenaar geprogrammeer' word, om sodoende laasleoomblik-verandering in die veld toe te laat. Dic draaghare rekenatar vertoon en bêre dili intyds in onverwerkle vorm teen 'n monstertempo van 2() ms.

\section{RESULTATE}

Aanvanklik is baie probleme ervala weens die feil dal die voertuig lading opgehou het vanal die teerpad met gevolglike onhanteerbare ruis op die elektrostatiese sensors. Diar is dus besluit om die eksperiment verder op 'n grasoppervlakte uil ic voer

In die begin is dic kollektorplate horisonlaal geplatas, en is gevind dat 'n sterk roltemposcin binne die gemete hoeksein teenwoordig is. Dit is omdat die gemete stroom allhanklik is 
van die hoeveclheid verskilladings wat op die vlerkpunte teenwoordig is, maar ook die tydsinterval walaroor die ladings gemeet word. Deur die vlerk te rol, word dalar meer ladings per tydseenheid op die kollektorplate ontvang en dit vertoon as 'n temposein.

Hierdie opskepeliek is verklein deur die kollektorplate vertikalal te monteer. Die temposein is nictemin nog steeds teenwoordig. Dit kan verklaar word uit die ionisasiegebied wat 'n belastraler veroorsaak. Dit beleken dat die temposein altyd tecnwoordig sal wees, soos gesien kan word in liguur 2. Dit is egter nie 'n problecm vir beleerdoeleindes nie. mits die rolbeheerder bewus is van hicrdie temposein.

Die vertikale elektrostatiese veld variecr baic. soos opgemerk

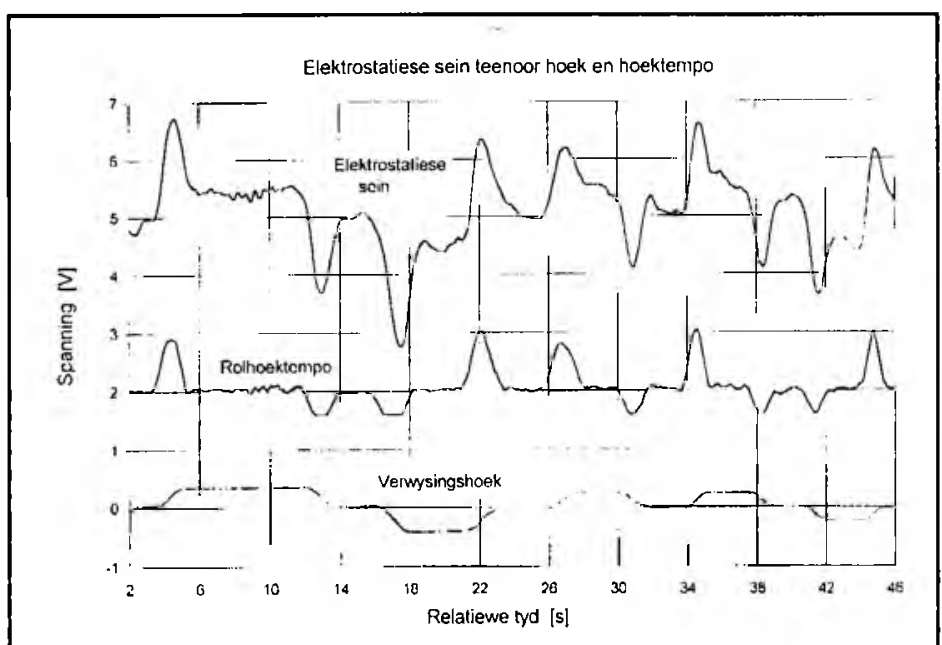

FIGUUR 2: Gemete elektrostatiese sein.

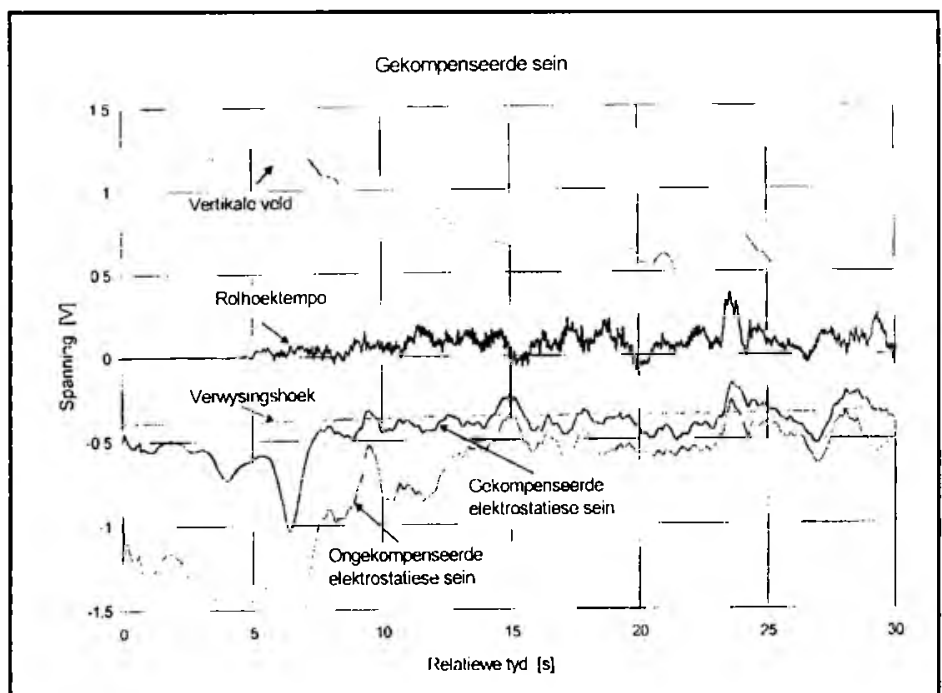

FIGUUR 3: Gekompenseerde elektrostatiese sein kan word vanuit figutr. 3. Dit is vermoedelik te wyle all sleurings vanal die omringende bome wala die eksperiment gedoen is. Die ellek sall verminder sodra dalar weg vall die grond all beweeg word. Ongeag die groot steurings (en die vermindering in veldsterkle), kan noglans gesien word dat dic gekompenseerde sein die verwysingshock volg.

Die resultate van figutur 3 toon verder dal die gemeto veldsterkte ongeveer twee keer groter is wanneer die vlerk stilstaan teenoor wanneer dit beweeg. Hierdie opnane is gedoen vanal stilstand tol by 'n snelheid van sowal $60 \mathrm{~km} / \mathrm{h}$. 'n Verklaring kan wees dat indien die opstelling staties is, "n lokale versadiging van geïonisecrde deeltjies om die vlerkpunte voorkom. met die gevolg dat 'n sterker sein dan gemeet word.

Op die vertikale as in ligure 2 en 3 word dic groottes van die rolhocklempo en verwysingshoek in lerme van 'n spanningsein alangetoon. Een volt vertecnwoordig 'n rolhocktempo van $33^{\circ} / \mathrm{s}^{\mathrm{s}}$ en 'n verwysingshock vall 9()$^{\circ}$.

\section{GEVOLGTREKKINGS}

Dalar is alangeloon dat hoogleverskille (lussen die vlerkpunte valn 'n vliegtuig hyvoorbeeld) gemeel kall word deur die spanningsverskil lussen geïsolecrde sensors (op (lie vliegtuig se vlerkpunte) te meet. Hierdic spanningsverskil ontstaan as gevolg van ladingsverskille in die atmosfeer onder die invloed van die aarde se elektrostaliese veld.

Tweedens is 'n tweedimensionele sensoropstelling ontwikkel wat dit moontlik makk om die stelsel binne reclelike perke ongevoclig te malk vir variasies in die atmosfeer se elektrostatiese veld. Verdere ondersocke sal titgevoer word om te bepaal wall die beperking is op hierdic metode van kompensasie.

Hierdie sensorstelsel is eksperimented geëvalueer en die resultate toon baic potensialal vir verdere navorsing.

\section{R.P. JANKOWSKI en G.P. HANCKE:}

Departement Elektriese en Elektroniese Ingenieurswese. Universiteil van Pretoria, Pretoria, 00)2

\section{IITERATUURVERWYSINGS}

I. Hill, M.L. (1972). Introducing Uhe Electrostatic Autopilot, Astronaru of Aermant, vol. 10, no, I, 22-31.

2. Hill, M.L. (1984). Electrostatic Autopilots. Jo/m /lopkins All Teclurical Digest, vol. 5, no. 2, 177-182.

3. Price, W.J. (1964). Naclear Radiation Detertion (McGiaw Ilill. New York).

4. Smith, C.M.H. (1965). Nurlear Plisics (Pergamon l'ress, New York)

*Outeur an wie korrespondensie gerig kan word 